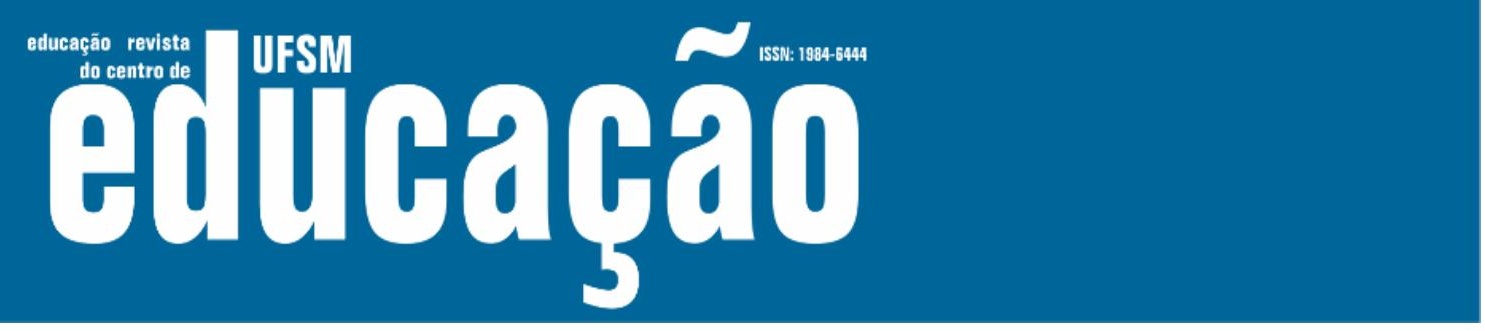

ISSN: 1984-6444 | http://dx.doi.org/10.5902/1984644436288

\title{
Reforma do Estado e Políticas de Avaliação da Qualidade da Educação Básica no Brasil
}

State reform and basic education quality assessment policies in Brazil

Késia Silva Tosta

Assistente Social, doutora em Política Social e professora substituta da Universidade Federal de Ouro Preto, Mariana, Minas Gerais, Brasil.

kesia-tosta@hotmail.com - https://orcid.org/0000-0001-9154-828X

\section{Marlon Gomes Ney}

Professor doutor na Universidade Estadual do Norte Fluminense Darcy Ribeiro, Campos dos Goytacazes, Rio de Janeiro, Brasil.

marlonney@uenf.br - https://orcid.org/0000-0002-0302-6818

Renata Maldonado da Silva

Professora doutora na Universidade Estadual do Norte Fluminense Darcy Ribeiro, Campos dos Goytacazes, Rio de Janeiro, Brasil.

maldonadoren27@gmail.com - https://orcid.org/0000-0001-7901-623X

Recebido em 07 de janeiro de 2019

Aprovado em 09 de janeiro de 2019

Publicado em 24 de junho de 2020

\section{RESUMO}

A partir da revisão bibliográfica este ensaio tem como objetivo identificar o percurso histórico e os alicerces de destaque da teoria neoliberal e sua influência no Brasil a partir do início da década de 1990 até o início do século XXI, e as consequências sobre a política de educação básica. Esse período é marcado pela recente redemocratização do país e estabelecimento legal das políticas sociais, entre elas a política de educação. Mas nesse momento de consagração de direitos, começa o processo de (contra) reforma do Estado. A política de educação teve destaque dentro das reformas neoliberais, no qual um dos principais instrumentos utilizados foram as avaliações em larga escala. A partir da adoção de receituários neoliberais, vê-se a negação dos preceitos constitucionais e a deficitária afirmação de direitos sociais. Para análise e problematização dessa temática, este artigo se divide em duas partes: i) "A Reforma do Estado e seus desdobramentos na política de educação brasileira", que aborda a emergência da teoria neoliberal, seu alastramento no Brasil e impacto na política de educação; e ii) "Avaliação em Larga Escala”, que trata a forma como se dá a avaliação de políticas sociais, em especial na educação básica em larga escala. Compondo o trabalho também há as seções de introdução e considerações finais.

Palavras-chave: Reforma do Estado; Avaliação; Política de Educação. 


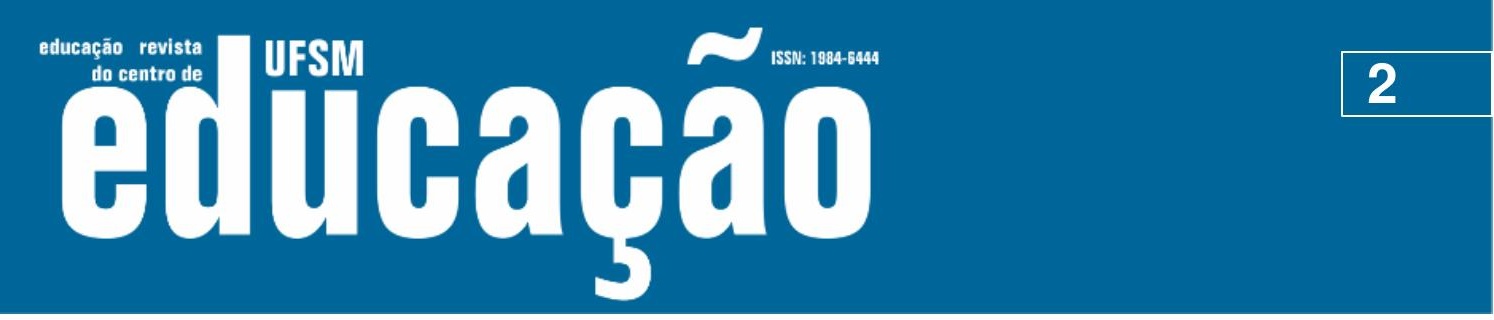

ISSN: 1984-6444 | http://dx.doi.org/10.5902/1984644436288

\section{ABSTRACT}

As from the bibliographic review this essay aims to identify the historical course and the foundations of neoliberal theory and its influence in Brazil from the early 1990s to the early 21 st century, and the consequences on basic education policy. This period is marked by the recent redemocratization of the country and the legal establishment of social policies, including education policy. However, in this moment of consecration of rights, the process of (counter) state reform begins. Education policy was prominent within the neoliberal reforms, in which one of the main instruments used was the largescale evaluations. From the adoption of neoliberal prescriptions, one can see the denial of constitutional precepts and the deficient affirmation of social rights. For the analysis and problematization of this theme, this article is divided into two parts: i) "State Reform and its consequences in Brazilian education policy", which addresses the emergence of neoliberal theory, its spread in Brazil and its impact on education policy.; and ii) "Large-Scale Evaluation", which deals with how social policies are evaluated, especially in large-scale basic education. Composing the work there are also the introduction and final considerations sections.

Keywords: State Reform; Evaluation; Education Policy.

\section{Introdução}

A Reforma do Estado no Brasil se inicia nos anos de 1990, influenciando a forma das políticas sociais a partir da adoção de critérios de gestão empresarial, privatização e parcerias público-privada. Entre as políticas sociais impactadas pela reforma neoliberal no país está a educação.

A partir da Constituição de 1988, a política de educação é considerada uma política de direito universal e obrigação do Estado, direito esse alcançado a partir das lutas dos profissionais da área na década de 1980, que compreendiam que, além da garantia de acesso, também deveria haver qualidade, sendo necessário a análise contínua com vistas ao seu desenvolvimento.

Porém, com o advento do neoliberalismo no país, a proposta de construção de outros parâmetros para as políticas educacionais, provenientes das reivindicações de amplos setores da sociedade civil foram negligenciadas. Instaurou-se o predomínio do mercado com a instância mais eficiente para nortear as políticas educacionais, além da incorporação das determinações de organismos mundiais, tais como o Banco Mundial, que, vinham desde meados da década de 1970, propondo mecanismos 


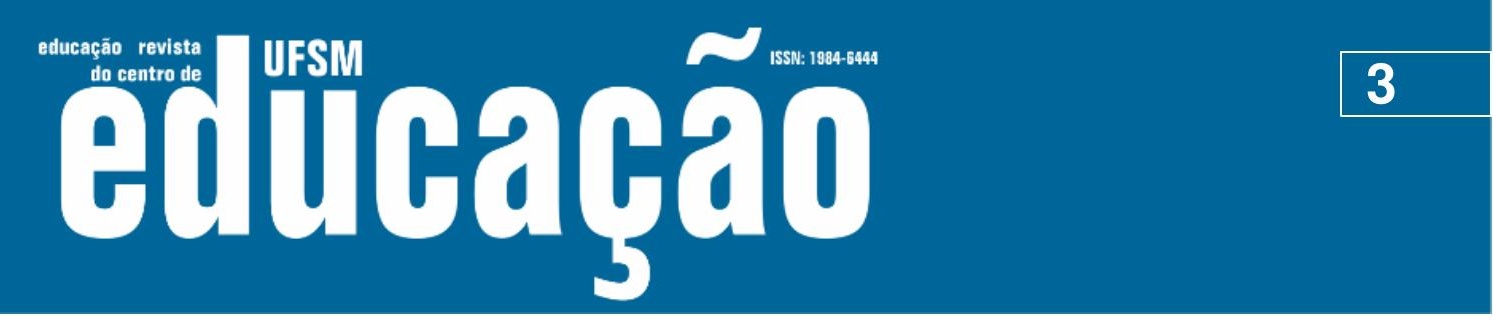

ISSN: 1984-6444 | http://dx.doi.org/10.5902/1984644436288

visando 'melhorias' no campo educacional dos países periféricos. Entre uma das recomendações com o objetivo de aprimorar a 'qualidade' da educação que vinha sendo ofertada pelos países-membros, encontra-se a avaliação em larga escala, que passou a ser instaurada em âmbito nacional.

Nesse cenário, o presente estudo tem como objetivo analisar as implicações sobre as políticas educacionais brasileiras, no contexto da (contra) Reforma do Estado (BHERING, 2008) implementada no país, a partir da década de 1990. Os desdobramentos do projeto neoliberal serão discutidos a partir da instauração das políticas de avaliação em larga escala como o principal parâmetro para aferir a qualidade ofertada pela educação básica. Buscando atingir esse propósito, esse trabalho é dividido em dois itens: "A reforma do Estado e seus desdobramentos na política de educação brasileira", que tem como objetivo analisar a reforma do Estado em âmbito nacional e seu impacto nas políticas de educação básica ; e "Avaliação em Larga Escala", que aborda o processo de organização das avaliações em larga escala na educação básica no país e as principais críticas dos autores. O marco temporal deste trabalho inicia-se na década de 1990, a partir da adesão do Estado brasileiro aos preceitos neoliberais e ao processo de contra-reforma no país, assim como a análise das implicações desse modelo no início do século atual.

\section{A reforma do Estado e seus desdobramentos na política de educação brasileira}

De acordo com Harvey (2005), o neoliberalismo é uma teoria de práticas político-econômicas que defende que o bem-estar humano só pode ser alcançado a partir das liberdades empreendedoras individuais, que deve ser garantido em primeira instância os "direitos à propriedade privada, livre mercados e livre comércio" (HARVEY, 2005, p.12). Para isso, é necessário que o Estado garanta esse ambiente, intervindo o mínimo possível na economia.

Essa corrente de pensamento começou a se despontar pelo mundo nas décadas de 1970 e 1980 e conseguiu notoriedade popular pelo fato de ter um discurso que incide sobre desejos e sensações da sociedade. Assim, o neoliberalismo se 


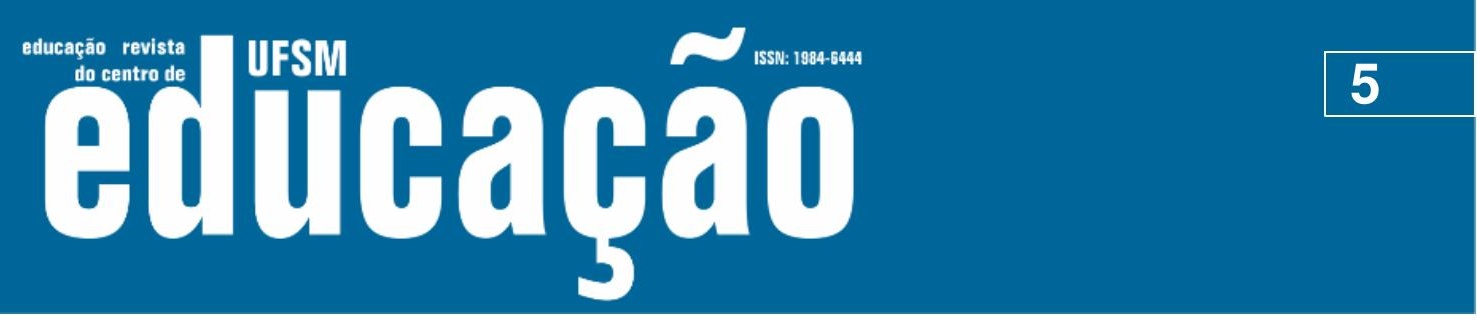

ISSN: 1984-6444 | http://dx.doi.org/10.5902/1984644436288

Em 1988, a Constituição da República Federativa do Brasil, marco de um amplo processo de discussão entre as diversas classes sociais da sociedade brasileira, cuja pauta política tinha como principal destaque a revalorização do espaço público e a democratização das relações entre Estado e a sociedade, consagrou alguns direitos que a diferencia das constituições anteriores. Para os objetivos desta comunicação destaco em primeiro lugar, a consagração de políticas estatais de caráter universalizante, enquanto direito do cidadão e dever do Estado. Em segundo lugar, a Constituição Federal de 1988 adotou como princípio que 'todo poder emana do povo, que o exerce por meio de representantes eleitos, ou diretamente, nos termos desta constituição' (CF, artigo $1^{\circ}$, parágrafo único). Em respeito a este princípio, a 'participação da comunidade' ou uma 'gestão democrática' foram previstas no processo decisório das políticas estatais, sendo posteriormente regulamentadas através das leis ordinárias que definiram o caráter, a composição e as competências dos mecanismos de participação.

Assim, a Constituição de 1988 reconheceu os direitos sociais, destacando a obrigação do Estado na realização de políticas sociais com a participação da sociedade civil no seu controle. No que concerne à política de educação, ela contemplou reivindicações dos movimentos de educadores e resgatou o caráter da educação como política social universal, sendo dever e obrigação do Estado, com a garantia da participação popular (SANTOS, 2011). No artigo 60 da Constituição, a educação foi reconhecida como o primeiro dos direitos sociais, como também direito político e civil. Esta formalização no ordenamento jurídico do país significa o reconhecimento de que ela faz parte das dimensões estruturais da própria consistência do ser humano e fator indispensável da vida social (CURY, 2012).

Porém na década de 1990, no momento que o Brasil começava a experimentar momentos de democratização e viabilização de políticas sociais, o Estado brasileiro sofre a influência da teoria neoliberal, que como alerta Silva (2000, p.1), "elege como principal alvo de ataque os direitos sociais consagrados na Constituição Federal de 1988, responsabilizando pela crise econômica e política do momento".

O início dos anos 1990 é caracterizado no Brasil pela instabilidade e crise financeira, e de acordo com a teoria neoliberal não é o capitalismo que está em crise, e sim o Estado. Então, o país encontrava-se nessa condição crítica, pelo excessivo gasto do Estado com políticas sociais que desencadeou a crise fiscal, sendo necessário sua reestruturação. Assim, era necessário diminuir a atuação do Estado a partir da oferta de políticas sociais como também dos mecanismos governamentais de participação popular, pois para ela "as instituições democráticas, além de mais 


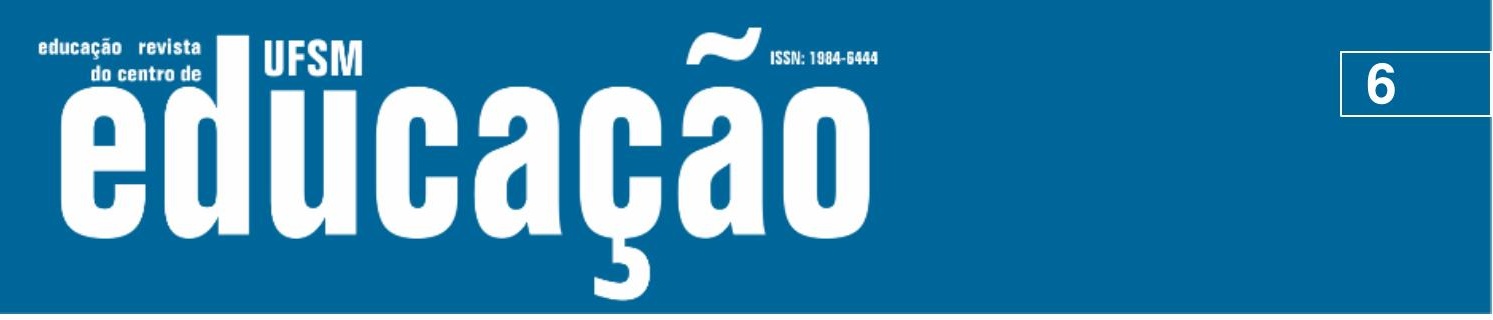

ISSN: 1984-6444 | http://dx.doi.org/10.5902/1984644436288

permeáveis às pressões e demandas da população, perdiam em eficiência se comparada as do mercado" (PERONI; ADRIÃO, 2004, p.139).

A reforma do Estado que iniciou nos anos 1990, no Brasil, além de ter sido amparada na retórica neoliberal, também foi influenciada pela perspectiva teórica da terceira via, que é baseada no modelo socialdemocrata europeu. Esta possui em comum com o neoliberalismo o diagnóstico de que o responsável pela crise é o Estado intervencionista, mas ressaltando o problema gerencial, propondo como solução as parcerias públicas e privadas (PERONI, et,al, 2009).

A proposta [...] é reformar o Estado, mas como tem o diagnóstico de que o Estado é ineficiente, essa reforma deve ter o mercado como parâmetro de qualidade. E com esse diagnóstico, o Estado não deve ser mais o principal executor das políticas sociais, que devem estar sob o protagonismo da sociedade civil através do terceiro setor. Assim, o terceiro setor é uma das alternativas propostas pela Terceira Via, tanto para que o Estado não seja mais o principal executor das políticas sociais como para que o conteúdo mercantil possa, através das parcerias, aprofundar a lógica de mercado nas políticas públicas, "qualificando-as". É o que Giddens chama de sociedade civil modernizada, empreendedora (PERONI, 2013, p.13).

Essa modalidade de reforma do Estado é apresentada de fato como uma terceira possibilidade de organização econômica, ao lado das políticas keynesianas e neoliberais. Entretanto o diagnóstico do motivo da crise é exatamente o mesmo da teoria neoliberal, assim como o fato de que "o Estado não deve ser o executor das políticas sociais" (PERONI, 2013, p.12).

A reforma do Estado no Brasil teve seus primeiros passos no governo de Fernando Collor de Melo (1990-1992), tendo continuidade no governo Itamar Franco (1992-1994), mas foi definitivamente consolidada no primeiro mandato do governo Fernando Henrique Cardoso (de 1995 a 1998), através do Ministério da Administração Federal e Reforma do Estado, o MARE, sob a liderança do ministro Luiz Carlos Bresser Pereira (SILVA, 2000).

O MARE foi criado para orientar o processo de reforma no país, fomentando as privatizações, terceirizações e publicizações. Dessa forma, a parceria público-privado ganhou notoriedade, fortalecendo a perspectiva empresarial nos serviços públicos como saúde, assistência, previdência e educação (SILVA, 2000). 


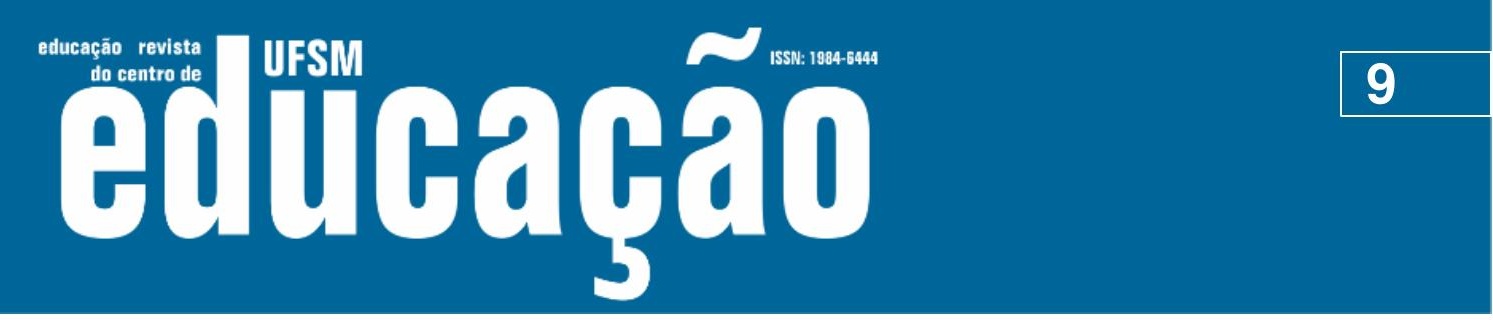

ISSN: 1984-6444 | http://dx.doi.org/10.5902/1984644436288

\section{Avaliação em Larga Escala}

A avaliação de políticas sociais é uma temática que vem crescendo a cada dia, servindo de base para realocar, melhorar e desenvolver as intervenções do Estado na sociedade. De acordo com autores como Faria (2005), Silva (2001) e Boschetti (2009), as técnicas de avaliação emergiram nos Estados Unidos na década de $1960 \mathrm{com}$ o objetivo de aferir ações públicas, objetivando identificar o que era mais eficaz, tendo em vista o grande gasto público do período e a falta de controle sobre eles. Dessa forma, buscava-se uma maior fiscalização e domínio dos gastos públicos (FARIA, 2005).

[...] a expectativa era, ainda, a de que a avaliação, ao superar o problema de déficit de compreensão acerca desses processos e de seu impacto, pudesse garantir a racionalidade dos processos decisórios e a legitimação das políticas e dos programas. (FARIA, 2005, p.98)

A avaliação se assemelha a um trabalho de pesquisa, pois ambas possuem harmonia em relação a vários pontos, como mostra Faria (1999, p. 42): "[...] o conteúdo substantivo dos fenômenos estudados; as técnicas de coleta, organização e análise de dados; e utilização dos resultados". Porém elas detêm diferenças, e de acordo com o autor citado, as especificidades da avaliação correspondem:

- do ponto de vista metodológico, a avaliação é uma atividade que obtém, combina e compara dados de desempenho com um conjunto de metas escalonadas;

- do ponto de vista de sua finalidade, a avaliação responde a questões sobre a eficácia/efetividade dos programas e, neste sentido, sua tarefa é julgar e informar;

- do ponto de vista de seu papel, a avaliação detecta eventuais falhas e afere méritos dos programas durante sua elaboração. Neste sentido, sua tarefa é formativa, permitindo a correção ou conformação de rumos. (FARIA, 1999, p. 42).

Dessa forma, a avaliação utiliza-se de métodos e técnicas da pesquisa social, mas seu objetivo é diferente, pois é uma atividade que se baseia em realizar julgamentos e aferições de uma determinada intervenção, para respaldar tomadas de decisão da política, programa ou projeto, tanto em sua implantação, implementação e resultados (DESLANDES, 1997). Aguilar e Ander-Egg (1994) dizem que avaliação é um tipo de "pesquisa social aplicada". Já a pesquisa é um processo sistemático de 


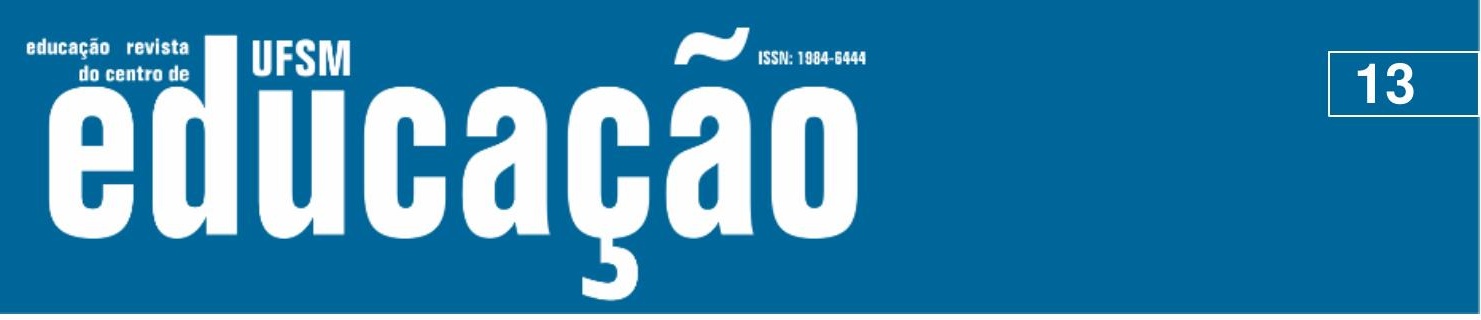

ISSN: 1984-6444 | http://dx.doi.org/10.5902/1984644436288

O Índice de Desenvolvimento da Educação Básica (IDEB) é formado pela avaliação do SAEB, a ANRESC (Prova Brasil) e pelo fluxo escolar. O índice é atualmente o principal instrumento para medir a qualidade da educação básica, sendo a base primordial para a tomada de decisões na gestão da política educacional.

De acordo com o INEP, a institucionalização do IDEB se deu pela necessidade de criar, em um único indicador, as ponderações e notas obtidas pelos alunos no SAEB e também a taxa de evasão e reprovação via fluxo escolar, julgando que as duas variáveis são as mais importantes para aferir a qualidade da educação.

Com a criação do modelo de avaliação da qualidade da educação via IDEB, foi 'incentivado' que os municípios e estados utilizassem formas de avaliação nos mesmos critérios (prova padronizada e fluxo escolar), e que os índices impactassem na gestão das secretarias de educação (BROOKE; CUNHA, 2011). Com o discurso de ampliar e melhorar os resultados do IDEB, o governo federal vem incentivando que os estados se utilizem de políticas de high-stake (forte impacto), que tem se destacado pelas políticas de bonificação salarial ou remuneração variável. Assim, a melhoria ou adicional ao salário dos professores fica condicionado aos resultados da escola no IDEB ou pelo indicador de qualidade educacional próprio de cada estado (LOPES, 2013).

É importante chamar a atenção para o fato de que, a implementação da avaliação em larga escala enquanto política de Estado trouxe impactos não só sobre as políticas de bonificação salarial, mas, sobretudo, no campo do currículo escolar. Sousa (2010), em seu estudo sobre a implementação da avaliação em larga escala no estado de São Paulo, por meio do SARESP - Sistema de Avaliação Escolar do Estado de São Paulo, criado em 1996, identificou a produção de um currículo unificado, que visava atender aos parâmetros de 'qualidade' enunciados na política de avaliação da educação básica implementada pelo estado. De acordo com a mesma autora, a partir de 2007, constatou-se uma estreita aproximação entre as matrizes curriculares do SARESP e o currículo oficial, orientando os materiais didáticos disponibilizados aos professores e alunos. Ressalta-se, portanto, que a política vem promovendo o controle sobre o trabalho docente e a definição do que deve ser 


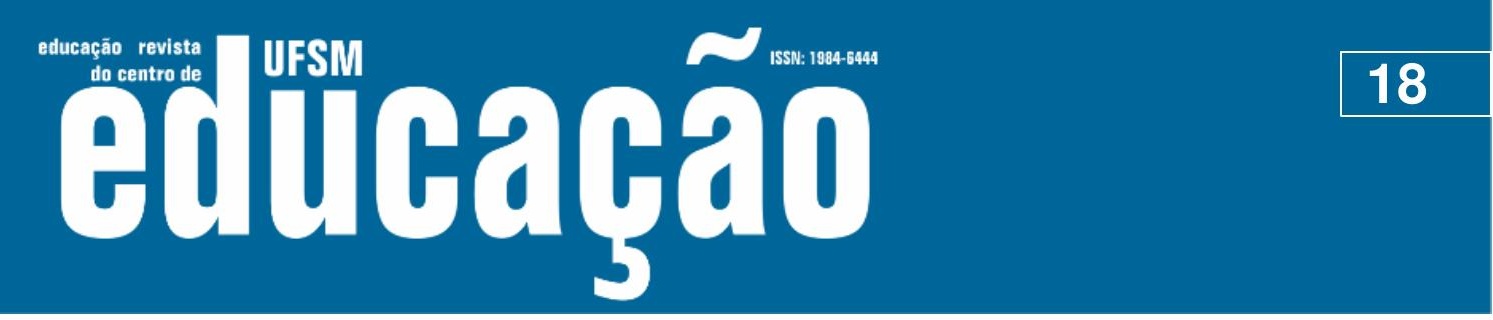

ISSN: 1984-6444 | http://dx.doi.org/10.5902/1984644436288

Dessa forma, o bom desenvolvimento econômico que a reforma neoliberal pode trazer ao país impacta somente nos grandes empresários, elites do país, sendo distante da massa da população que vem pagando a "conta" das reformas econômicas e sendo excluída do processo, no momento em que as políticas sociais, como por exemplo a educação, não são oferecidas de maneira efetiva e democratizada. Assim, se apropriando de Peroni (2003), nossas políticas sociais atuais estão sem direitos sociais.

\section{Referências}

AGUILAR, M. J. \& ANDER-EGG E. Avaliação de serviços e programas sociais. Petrópolis: Vozes, 1994.

BARDANACHIVILI, Elaine. Avaliações nacionais ignoram processo de evolução da escola. Jornal do Brasil, 17 dez. 2000. Educação e Trabalho - empregos, p.3-5.

BEHRING, Elaine Rossetti. Brasil em contra-reforma: desestruturação do Estado e perda de direitos. 2ª edição - São Paulo: Cortez, 2008.

BONAMINO, Alicia Maria Catalano de.; SOUSA, Sandra Záquia. Três gerações de avaliação da educação básica no Brasil: interfaces com o currículo da/na escola. Educação e Pesquisa, São Paulo, v.38, n.2, p.373-388, abr./jun.2012.

BONAMINO, Alicia Maria Catalano de. Tempos de avaliação educacional: o SAEB, seus agentes, referências e tendências. Rio de Janeiro: Quartet. 2002.

BONAMINO, Alicia Maria Catalano de; FRANCO, Crespo. Avaliação e política educacional: o processo de institucionalização do SAEB. Cadernos de Pesquisa, n.108, São Paulo: Fundação Carlos Chagas/Autores Associados, Nov.,p.101-132, 1999.

BOSCHETTI, Ivanete. Avaliação de Políticas, Programas e Projetos Sociais. In: CFESS;ABEPSS (org). Serviço Social: Direitos Sociais e Competências Profissionais. 1 ${ }^{a}$ edição. Brasília: CFESS, 2009, v.1, p.575-592.

BROOKE, Nigel; CUNHA, Maria Amália de Almeida.; FALEIROS, Matheus. Avaliação Externa como instrumento da Gestão Educacional nos Estados. Relatório Final. GAME/FAE/UFMG. Agosto, 2011.

CÁRIA, Neide Pena; OLIVEIRA, Sandra Maria da Silva SALES. Avaliação em larga escala e a gestão da qualidade da educação. Revista de Ciências Humanas Educação, FW, v. 16, n. 26, p. 22-40, Jul. 2015. 


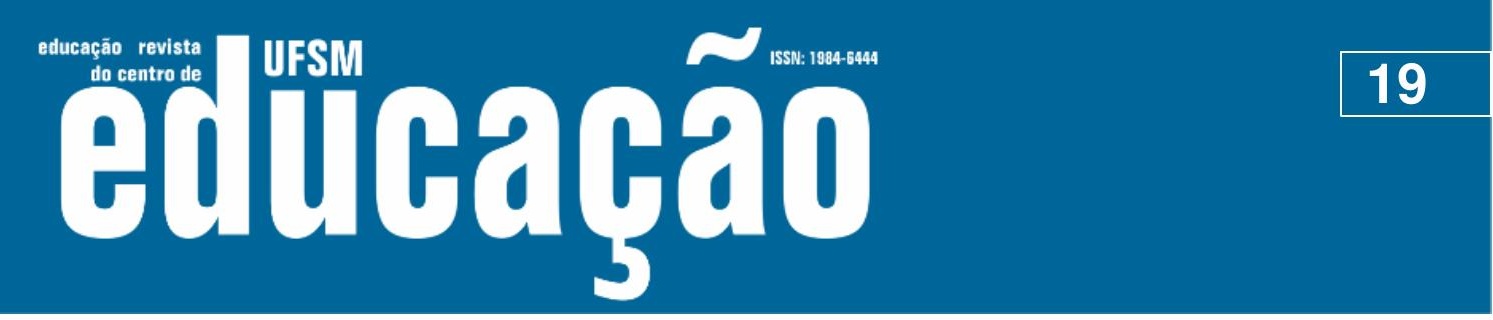

ISSN: 1984-6444 | http://dx.doi.org/10.5902/1984644436288

COMERLATTO, Luciani Paz; CAETANO, Maria Raquel. As parcerias público-privadas na educação brasileira e as decorrências na gestão da educação: o caso Instituto Ayrton Senna (IAS). In: PERONI, Vera (org.) Redefinições das fronteiras entre o público e o privado: implicações para a democratização da educação. Brasília: Liber Livro, 2013. pp.175-204.

CURY, Carlos Roberto Jamil. Educação como direito social. Dicionário de Políticas Sociais/ Organizadores: Carmem Lúcia Freitas de Castro, Cynthia Rúbia Braga Gontijo, Antônio Eduardo de Noronha Amabile. Barbacena: EDUEMG, 2012.

DAGNINO, Evelina. ¿Sociedade civil, participação e cidadania: de que estamos falando? Em Daniel Mato (coord.), Politicas de ciudadania y sociedad civil em tiempos de globalización: FACES, Universidad Central de Venezuela, pp. 95 - 110, 2004.

DESLANDES, Suely Ferreira. Concepções em pesquisa social: Articulações com o campo da avaliação em serviços de saúde. Cadernos de Saúde Pública, nำ13, p.103107, 1997.

DOURADO, Luiz Fernandes. As transformações da sociedade contemporânea, o papel do Banco Mundial e os impactos na educação superior brasileira. In: SILVA, Rinalva Cassiano. (Org.). Educação para o século XXI: dilemas e perspectivas. Piracicaba: Editora UNIMEP, 1999.

FARIA, Carlos Aurélio Pimenta de. A Política da Avaliação de Políticas Públicas. Revista Brasileira de Ciências Sociais, Vol.20, nํ59, Outubro de 2005.

FARIA, Regina. Avaliação de Programas Sociais: evolução e tendências. In: RICO, Elizabeth Melo (Org.). Avaliação de Políticas Sociais: uma questão em debate. São Paulo: Cortez: Instituto de Estudos Especiais, 1999, p.41-49.

FISCHER, Beatriz Terezinha. Daudt. Avaliação da aprendizagem: a obsessão pelo resultado pode obscurecer a importância do processo. In: Avaliação em larga escala:foco na escola. Flávia Obino Werle (org). São Leopoldo: Oikos; Brasília: Liber Livro, 2010.

FREITAS, Luiz Carlos. de. Eliminação Adiada: o caso das classes populares no interior da escola e a ocultação da (má) qualidade do ensino. Educação Sociedade, Campinas, vol.28, n.100 - Especial, p.965-987, out.2007.

FREITAS, Luiz Carlos de. A importância da avaliação: em defesa de uma responsabilização participativa. Em Aberto, Brasília, n.96, p.127-137, maio/ago, 2016.

HARVEY, David. O Neoliberalismo: histórias e implicações. Tradução: Adail Sobral e Maria Stela Gonçalves. Edições Loyola, Inglaterra, 2005. 


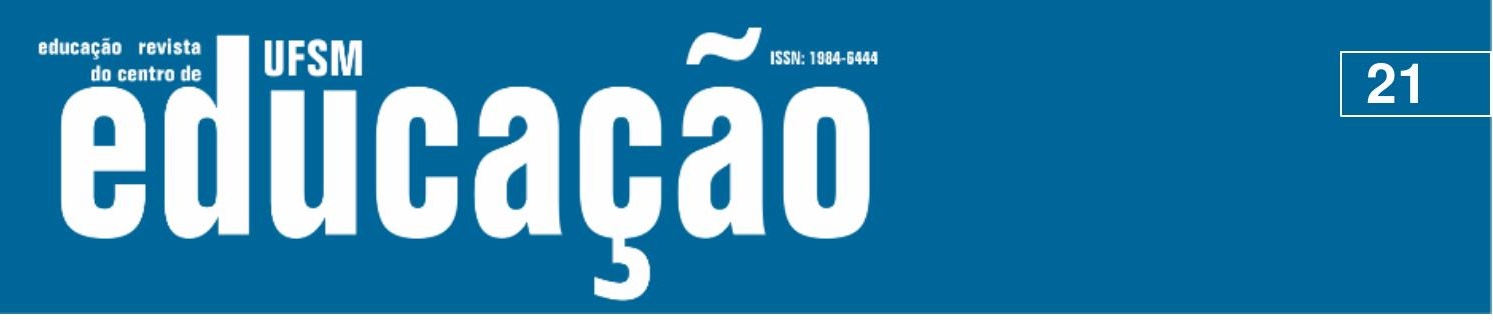

ISSN: 1984-6444 | http://dx.doi.org/10.5902/1984644436288

SANTOS, Jean Mac Cole Tavares. Exame Nacional do Ensino Médio: entre a regulação da qualidade do Ensino Médio e o vestibular. Educar em Revista, Curitiba, Brasil, n.40, p.195-205, abr./jun.2011. Editora UFPR.

SAVIANI, Demerval. O Plano de Desenvolvimento da Educação: análise do projeto do MEC. Educação e Sociedade, Campinas, v-28, n.100 - Especial p. 1231-1255, out. 2007.

SILVA, Ilse Gomes. A Reforma do Estado brasileiro nos anos 90: processo e contradições. IV Congresso Português de Sociologia, 2000, Coimbra. Cadernos de resumo, 2000. v.1.p.1-13.

SILVA, Maria Ozanira Silva e (org.). Avaliação de políticas e programas sociais: teoria e prática. São Paulo: Veras, 2001.

SOLANO, Cleonice Halfeld. As políticas educacionais gerencialistas e o PDE-Escola. In: RODRIGUES, Rubens Luiz (org.) Educação Escolar no século XXI. Juiz de Fora, MG: Editora UFJF, 2013 pp.79-97.

SOUSA, Sandra Zákia; Arcas, Paulo Henrique. Implicações da avaliação em larga escala no currículo: revelações de escolas estaduais de São Paulo. Educação: Teoria e Prática - v. 20, n.35, jul.-dez.-2010, p. 181-199.

SOUSA, Sandra Zákia. Concepções de qualidade da educação básica forjadas por meio de avaliações em larga escala. Avaliação, Campinas; Sorocaba, SP, v.19, n.2, p.407-420, jul. 2014.

TORRES, Rosa Maria. Melhorar a qualidade da educação básica? As estratégias do Banco Mundial. In: O Banco Mundial e as Políticas Educacionais. Livia de Tommasi, Mirian Jorge Warde, Sérgio Haddad. (org.) Cortez, 6ㄹeㄹ. 280p., 2007.

WERLE, Flávia Obino Corrêa. Sistema de avaliação da educação básica no Brasil: abordagem por níveis de segmentação. In: Avaliação em larga escala: foco na escola. Flávia Obino Werle (org). São Leopoldo: Oikos; Brasília: Liber Livro, 2010.

\section{Correspondência}

Késia Silva Tosta - Universidade Federal de Ouro Preto, Instituto de Ciências Sociais Aplicadas - Rua do Catete, 166, Mariana, Minas Gerais, 35420-000.

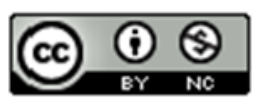

This work is licensed under a Creative Commons Attribution-NonCommercial 4.0 International (CC BY-NC 4.0) 


\title{
N

ISSN: 1984-6444 | http://dx.doi.org/10.5902/1984644436288

\section{Notas}

\begin{abstract}
${ }^{1}$ Também conhecidas como políticas de Estado de Bem Estar Social ou Welfare State que ocorreu nos países centrais após a $2^{\mathrm{a}}$ Guerra Mundial. Essas políticas keynesianas (nome denominado por causa de seu maior teórico e defensor: Keynes) tinham o Estado como o responsável por controlar ciclos econômicos combinando políticas fiscais e monetárias. As políticas eram direcionadas para o investimento público, garantiam o pleno emprego e a complementação dos salários dos trabalhadores através da seguridade social, assistência médica, educação e habitação (HARVEY, 2005).

${ }^{2}$ O Programme for internation Student Assessment (PISA) é um programa internacional de avaliação dos estudantes, aplicada a estudantes na faixa etária de 15 anos. É coordenado e desenvolvido pela Organização para Cooperação de Desenvolvimento Econômico (OCDE), mas em cada país há também uma coordenação nacional. No caso do Brasil é coordenado pelo Instituto Nacional de Estudos e Pesquisas Educacionais Anísio Teixeira (INEP). Fonte: http://portal.inep.gov.br/pisa-programa-internacional-de-avaliacao-de-alunos.
\end{abstract}

${ }^{3}$ Que se enquadram aos moldes do gerencialismo na gestão educacional, que é atribuição de gestão empresarial sobre as ações públicas (PARENTE, 2012). 